\title{
A SERVIDÃO VOLUNTÁRIA E O DISCURSO DE EMPREENDEDO- RISMO CULTURAL: APROXIMAÇÕES (TRISTES, MAS) POSSÍVEIS
}

\author{
Monique Nascimento* \\ Marina Coelho** \\ Larissa Ferreira Tavares*** \\ Márcio Silva Rodrigues*****
}

\begin{abstract}
Resumo
Objetivamos, neste trabalho, discutir possíveis aproximações entre a ideia de empreendedorismo e a servidão voluntária dos trabalhadores artistas a partir da análise do Cultura Gera Futuro - campanha federal, amplamente veiculada, que centralizou as ações do Ministério da Cultura no ano de 2018. Utilizamos para análise do conteúdo da campanha dados do site oficial e da observação não participante realizada na etapa de circuito de divulgação realizada em Florianópolis/SC. Pudemos evidenciar, a partir do estudo, a vinculação da figura do artista, no Cultura Gera Futuro, à imagem difundida de empreendedor de si, discurso que reforça e dissemina como positiva e natural uma forma sofisticada de dominação contemporânea.
\end{abstract}

Palavras-chave: Empreendedorismo. Trabalho artístico. Servidão voluntária.

\footnotetext{
* Doutoranda em Administração pela Universidade Federal de Santa Catarina (UFSC). Florianópolis, SC, Brasil. E-mail: moniquenn@gmail.com.

** Doutoranda em Administração pela Universidade Federal de Santa Catarina (UFSC). Florianópolis, SC, Brasil. E-mail: marinacoelho.nina@gmail.com.

*** Doutoranda em Administração pela Universidade Federal de Santa Catarina (UFSC). Professora Assistente do Instituto de Ciências Econômicas, Administrativas e Contábeis da Universidade Federal do Rio Grande (FURG). São Lourenço do Sul, RS, Brasil.E-mail: larissaftavares@gmail.com.

**** Doutor em Administração pela Universidade Federal de Santa Catarina (UFSC). Professor Adjunto do Departamento de Administração da Universidade Federal de Pelotas (UFPel). Pelotas, RS, Brasil. E-mail: marciosilvarodrigues@gmail.com.
} 


\section{Contextualização}

A opressão se moderniza estendendo-se por todas as partes, as formas de mistificação que permitem ocultar nossa condição de escravos. Mostrar a realidade tal qual é na verdade e não tal como mostra o poder constitui a mais autêntica forma de subversão. (BRIENT; FUENTES, 2009, p. 2).

Procuramos, a partir da análise da campanha federal Cultura Gera Futuro, discutir a relação entre a condição de servidão voluntária de trabalhadores artistas e o discurso de empreendedor de si, amplamente disseminado na nova fase de acumulação capitalista. Discurso, este, relacionado a uma série de estudos, desenvolvidos desde o início dos anos 2000 acerca do campo da cultura no Brasil, que abordam as implicações do avanço da esfera econômica - no sentido estabelecido por Guerreiro Ramos (1989) - ou dos pressupostos econômicos, em espaços tradicionalmente não econômicos.

O empreendedorismo desi está,neste sentido, diretamenterelacionado ao uso dos princípios da economia de mercado como lente analítica da sociedade como um todo, à reconfiguração do papel do Estado (passagem de um regime de Bem-Estar Social para uma concepção neoliberal que toma o Estado como um agente econômico) e à compreensão da ideia de empresa como um modelo universalmente generalizável: parece representar a síntese, a amálgama, do ideário neoliberal (FOUCAULT, 2008).

Ao produzir novas relações e novas formas de compreender o mundo, o neoliberalismo também produz/demanda uma nova concepção de indivíduo (DARDOT; LAVAL, 2016). Não faltam descrições para um novo modelo de homem: protagonista, ativo, pensante (AKTOUF, 2001), hipermoderno, impreciso, flexível, precário, fluído ou sem gravidade; que remetem, invariavelmente, à compreensão do sujeito essencialmente empresarial: um verdadeiro empreendedor para um mundo produtivista, alguém que assuma riscos, decida, suporte o estresse, alguém que coloque todas as suas qualidades a serviço da rentabilidade e que seja capaz de se implicar afetiva e subjetivamente com seu trabalho (GAULEJAC, 2014). O sujeito ideal deixa de ser o homem-trabalhador - ou, um corpo dócil, nos termos de Foucault (2008) - e passa a ser o homem-empresa (um empreendedor-de-si).

Frente a um cenário econômico, político e social instável, na busca pela sobrevivência, pela consecução de seus desejos e pela autorrealização, o sujeito não apenas se submete mas engaja-se aos imperativos do capital, servindo ativa e voluntariamente a um jogo cujas regras, que educam e governam tudo e todos, são essencialmente as regras do mercado (DARDOT; LAVAL, 2016). Lançar-se ao mercado é, assim, apresentado 
como um modo de vida estimulante, inspirador e atrativo. O trabalhador é levado a sentir-se o exclusivo responsável pelos resultados da mobilização criativa de seus talentos e competências, independentemente do contexto econômico/produtivo em que se insere competitivamente.

Estimulados a comportarem-se como empresas, indistintamente da situação, os sujeitos têm as fronteiras enfraquecidas, permeáveis, entre os tempos e espaços pessoais e de trabalho: abertas para a colonização do primeiro pelo segundo. Os critérios de mercado passam, assim, a regular de forma ainda mais totalitária os demais enclaves da vida humana, a partir de um ideário sujeitador e mantenedor do sistema capitalista. Perguntamo-nos se este processo estende-se a, ou pode ser observado, apenas em profissões sobre as quais a economia de mercado constituiu seu desenvolvimento?

À primeira vista, a resposta é não. $\mathrm{O}$ avanço da economia de mercado pode ser verificado nos mais diversos espaços e formas de trabalho, inclusive naquelas historicamente marcadas pela resistência, como é o caso dos trabalhadores da cultura. Menger (2005), atualmente, diz que não se observam mais as representações herdadas do século XIX, que tinham como opostos o idealismo sacrifical do artista e o materialismo do trabalho calculado ou, mais ainda, a figura do criador, insubmisso e original, versus aquela do burguês ocupado com a estabilidade das normas e convenções sociais. Nos dias atuais, segundo o autor, o artista tem sido percebido quase como encarnação do trabalhador do futuro: um profissional inventivo, móvel e intrinsecamente motivado.

De fato, a própria consolidação de áreas como a economia da cultura e a economia criativa corroboram as considerações do autor supracitada, uma vez que, em muitas de suas discussões, percebemos uma figura claramente influenciada pelo ideário neoliberal: o empreendedor cultural. $\mathrm{Na}$ área dos estudos organizacionais, as discussões sobre empreendedor ou empreendedorismo cultural são bastante abrangentes e, normalmente, avaliadas positivamente. Por exemplo, em um dos trabalhos precursores sobre o tema, Green (2002) defende a necessidade de assumir a cultura como mercadoria e de se considerar seu alto potencial financeiro. $\mathrm{O}$ autor critica o repúdio ao comércio cultural e sua infundada oposição, a seu ver, à identidade/autenticidade cultural.

Assim como Green (2002), outros autores tomam o empreendedorismo cultural como forma potencial de saída da crise, como uma alternativa para o desenvolvimento de países periféricos (KHOURY; PRASAD, 2016) e, consequentemente, como um caminho inconteste e necessário à classe artística trabalhadora (LINDKVIST; HJORTH, 2015; ÜBERBACHER; JACOBS; CORNELISSEN, 2015; KHOURY; PRASAD, 2016; CARVALHO; CUTRIM; COSTA, 2017). 
Neste processo, há um esforço por parte dos pesquisadores em delinear "fatores estratégicos", "boas práticas" ou "indicadores de sucesso" e desenvolver modelos de medição, comparação, controle e avaliação das atividades artísticas enquanto "empreendimentos" (KAVOUSY et al., 2010, KREMP, 2010, CHEUNG LEUNG, 2013; LINDKVIST; HJORTH, 2015, ÜBERBACHER; JACOBS; CORNELISSEN, 2015; SARDANA, 2018).

Chama-nos a atenção, no entanto, a ausência de discussões, nos trabalhos mencionados, acerca dos paradoxos inerentes ao próprio termo "empreendedorismo cultural". Tampouco são levantadas considerações em relação às consequências da adaptação dos artistas e da arte a este "modelo de negócio". É neste sentido que empenhamos o esforço analítico deste trabalho. $\mathrm{Na}$ tentativa de desvelar as implicações negativas da emergência desse sujeito e do fenômeno que o acompanha, mobilizam-se discussões em diversas áreas (psicologia, sociologia, filosofia), com o intuito de ilustrar como o avanço do ideário neoliberal radicaliza a ideia de um indivíduo conscientemente sujeitado ou, nos termos deste trabalho, de um servo voluntário. Nossa opção pelo resgate do conceito de servidão voluntária, que remete ao século XVI e que se faz atual hodiernamente, para discussão do empreendedorismo, ilustra uma forma de dominação contemporânea e seus impactos sobre os indivíduos.

Como forma de atingir ao objetivo proposto: inicialmente, realizamos algumas reflexões a respeito do conceito de servidão voluntária e sua relação com a ideia de indivíduo empreendedor de si; logo após, apresentamos as bases teóricas e reflexões da temática do empreendedorismo cultural; descrevemos, então, os métodos de coleta e análise de dados operados na investigação, que envolveram análise de dados secundários, provenientes do site oficial da Campanha Cultura Gera Futuro, e observação não participante, na etapa do circuito referente a tal campanha, realizada na cidade de Florianópolis; discutimos, posteriormente, acerca da existência do discurso do empreendedor de si enquanto um ideário sujeitador sobre as condições de trabalho, não apenas nas profissões sobre as quais a economia de mercado constituiu seu desenvolvimento, e a servidão voluntária dele decorrente, a partir de uma análise da Campanha Cultura Gera Futuro; tecemos, por fim, algumas reflexões concernentes à problemática que esta investigação propõe.

\section{Servidão voluntária e empreendedorismo}

Étienne de La Boétie nasceu em 1530, na França, foi escritor, jurista e filósofo. Sua obra mais reconhecida, "Discurso da Servidão Voluntária", fora escrita no século XVI e postumamente publicada por seu amigo Montaigne. Vislumbrado como uma ode à liberdade, em tal obra, La Boétie 
1 "O homem é naturalmente livre e quer sê-lo, mas sua natureza é tal que se amolda facilmente à educação que recebe" (LA BOÉTIE, 2009, p. 50).
(2009) entende a servidão como resultado de um infortúnio histórico e parte da pergunta "por que obedecemos?" para tratar dos motivos que levam milhões a servirem voluntariamente.

Para La Boétie (2009), a servidão voluntária, diferente daquela que implica a coação e o uso de força, relaciona-se ao desejo que os humanos possuem de serem subjugados. Em conformidade com o autor, o humano nasce livre e servo de ninguém; mas, podendo escolher entre ser submisso ou livre, renuncia à liberdade e aceita o jugo.

Salientamos que, ao indagar a respeito de como um pode dominar muitos, La Boétie (2009) menciona a existência de um corpo produzido pelo dominador, composto por aqueles que lhe servem, que the concede seu poderio. Segundo o autor, ao se submeterem - e doarem - ao soberano, os sujeitos não acreditam estar alienando suas vidas. Pelo contrário, acreditam estar conferindo poder a si. Todavia, o povo é ludibriado pelo seu próprio desejo servil.

La Boétie (2009) discorre que muitos, nascidos ou não sob o jugo da servidão, servem por hábito. Desse modo, é o costume, à medida que o tempo passa, capaz de conduzir os seres humanos à servidão, de ensinarlhes a engolir o veneno da escravidão sem acharem amarga a sua peçonha e de desejá-la. Ou seja, no processo de socialização, o humano abandona o estado de natureza, de modo que o desejo de liberdade cede lugar ao de servidão ${ }^{1}$.

Assim, os sujeitos tendem a servir sem relutância e a fazer voluntariamente aquilo que seus antepassados possam ter feito por imposição. Após terem nascido sob o jugo, serem educados e alimentados na servidão, há certo contentamento em viverem nas condições em que se encontram e uma dificuldade na percepção de que existem outros bens ou direitos diferentes daqueles que encontraram. Circunstância em que são mobilizadas pequenas compensações, artimanhas religiosas e ardis legais para produzir ilusões. Destacamos, nesse sentido, que discursos proferidos, como aqueles sobre o bem público e o interesse geral, podem atuar nos desejos dos sujeitos (LA BOÉTIE, 2009).

Podemos identificar, nessa perspectiva, um distanciamento entre a servidão voluntária dos dominantes e dos dominados. Os primeiros servem, pois possuem o desejo de serem obedecidos pelos demais, servem com o desejo de dominar. Os dominados, porém, servem porque se consideram como impotentes diante do tirano. Para resistir ao tirano, Étienne de La Boétie, (2009, p. 37) refere que não é necessário lutar: "basta não lhes dar nada e não lhes obedecer, sem combatê-los ou atacá-los, e eles ficam nus e são derrotados".

Este distanciamento entre o servir voluntário do dominante e do dominado argumentado por La Boétie (2009) sofre um estreitamento a 
partir do ideal empreendedor em que o dominante é simultaneamente dominado, explorador de si e explorado por si. Daí a perversidade do discurso do empreendedor de si mesmo: a incapacidade de resistência, a obediência compulsória promovida por este novo modelo de produção/ trabalho. A releitura do discurso de La Boétie (2009) provoca-nos, nesse sentido, o pensar acerca das possibilidades de imbricamento da servidão voluntária e o discurso contemporâneo sobre empreendedorismo de si.

A cultura empreendimentista emergente, iniciada entre os decênios de 1980 e 1990, relaciona-se ao contexto do neoliberal do capitalismo flexível, em que a ideia de longo prazo torna-se obsoleta (SENNETT, 2009), em que o trabalho autônomo e os contratos temporários (não obstante à precariedade de suas condições) são amplamente disseminados como libertários, portanto, desejáveis. Trata-se de "uma ideologia do empreendedorismo que extrapola as fronteiras das empresas e se entrelaça no tecido social" (PAES DE PAULA, 2002, p. 142), pode ser contemplada como uma espécie de institucionalização da instabilidade (ROSENFIELD, 2011). O trabalhador torna-se um empreendimento, uma empresa, a mais valiosa que existe, o mercado se torna a vitrine onde esse indivíduo se expõe, se negocia e se vende (EHRENBERG, 2010).

Para Colbari (2007,p. 76), o empreendedorismo tem sido vislumbrado como, "[...] uma força social desencadeada por comportamentos, atitudes e valores que conduzem à inovação, à mudança, potencializando a geração de riqueza e a ação transformadora das condições sociais e políticas”. Na lógica desse discurso, o sujeito deve se converter em uma empresa e incorporar as características defendidas por ela (LAZZARATO, 2011). Tanto os trabalhadores, quanto os desempregados ou assalariados, são convidados a se tornarem empreendedores - ocuparem-se integral e irrestritamente com business (GAULEJAC, 2014). Segundo Barbosa (2011, p. 138), estamos testemunhando a tentativa de uma "[...] construção da imagem do empreendedor de si mesmo como o indivíduo capaz de vencer as incertezas e inseguranças da vida social dentro do contexto do capitalismo flexível”.

Nesse cenário, como menciona Foucault (2008) o espírito empreendedor é disseminado como uma forma de salvação em todos os sentidos: seja para abertura de negócio próprio (ideia de ser seu próprio patrão), "garantindo" seu emprego, ou como um perfil pessoal, internalizando características empreendedoras. Diante da insegurança e da instabilidade da atual fase do capitalismo, o imperativo é "empreender qualquer coisa", "o que simboliza uma criação pessoal, uma aventura possível para todos" (EHRENBERG, 2010, p. 48), o indivíduo é, assim, o único responsável por sua empregabilidade e condição enquanto trabalhador. Deve, nesse sentido manter-se constantemente disponível, flexível e capacitado para adaptar-se ao cenário profissional. O indivíduo é "convocado a tomar seu 
lugar e a fazer de si mesmo seu melhor patrimônio" (BENDASSOLLI, 2000, p. 217).

Conforme Gaulejac (2014, p. 110), a ideia agora não está mais em tornar indivíduos em corpos "úteis e dóceis", no sentido foucaultiano da sociedade disciplinar mas em fazê-los "canalizar o máximo de energia libidinal para transformá-la em força produtiva”. De acordo com o autor, o desejo passa a ser solicitado permanentemente: desejo de sucesso, necessidade de reconhecimento, gosto pelo desafio, recompensa pelo mérito individual (GAULEJAC, 2014). Os trabalhadores passam a aspirar desejos empresariais como sendo seus. A fronteira entre vida pessoal e trabalho torna-se cada vez mais porosa e a submissão livremente concedida. O sujeito na cultura empreendimentista encontra-se distante da instância de domínio externo que o coage a trabalhar, é coator de si mesmo, submetese voluntariamente aos discursos propagados.

Dentre os resultados desta dinâmica produtiva estão o surgimento de novas, e agravamento das recorrentes, patologias mentais no trabalho, o aumento do sofrimento, de suicídios e da violência no ambiente de trabalho (DEJOURS, 2012). A servidão voluntária está entre as três patologias concernentes ao trabalho que Mendes (2007) propõe fundamentado nas pesquisas desenvolvidas por Dejours. A sobrecarga e a violência são as demais, elencadas pelo autor, e estão intimamente relacionadas à anterior.

Sob um modelo de acumulação flexível, que, segundo Ferreira (2013) e Mendes (2007), deteriora laços coletivos de trabalho, de solidariedade e de confiança, a servidão voluntária pode ser compreendida como uma condição, "uma nova forma de escravidão moderna" (DEJOURS, 2005, p. 42) face ao projeto neoliberal.

A contemplação do discurso do empreendedor de si como modelo ideal de sujeito/trabalhador, parece-nos, nesse sentido, relacionada à ideia de servidão voluntária. Tal ideário será, no entanto, observável apenas em profissões sobre as quais a economia de mercado constituiu seu desenvolvimento? Como este discurso repercute nas formas de trabalho não convencionais como na arte? Para pensar as especificidades do discurso relacionado ao trabalho artístico versamos, a seguir, acerca do empreendedorismo cultural.

\section{Empreendedorismo cultural}

Com o avanço do neoliberalismo e a generalização dos princípios da economia de mercado para os mais variados espaços sociais, verificamos a emergência de termos como "economia da cultura" e "economia criativa". Tais termos, que poderiam ser considerados oximoros em função da oposição existente entre o simbólico e o econômico, passam a ser amplamente 
divulgados, legitimados e estimulados, uma vez que a ideia de cultura como um negócio tornou-se, de forma mais intensa, um dos elementos responsáveis pelo desenvolvimento econômico e, consequentemente, mais presente nas agendas governamentais (THROSBY, 2001; MENGER, 2005; BENHAMOU, 2007; LOACKER, 2013).

Diante desse cenário, no qual as formas de trabalho são flexibilizadas (a partir da terceirização, dos contratos temporários, do trabalho intermitente, de tempo parcial, da ausência de seguridade social), observamos um lento processo de reposicionamento discursivo no qual o artista passa a ser relacionado ao (identificado como) empreendedor (LOACKER, 2013). Conforme Paes de Paula (2000, p. 142) afirma "reforçando um culto sem culpa à personalidade e ao sucesso", o empreendedorismo como forma de salvação e a ideia de indivíduo empreendedor de si são disseminados através de um discurso de responsabilização crescente dos indivíduos, seja pela criação do seu próprio emprego ou pelo desenvolvimento das suas competências (KOVÁCS, 2001).

Michetti e Burgos (2016, p 585) entendem por empreendedor cultural: "indivíduos e/ou grupos, formalizados ou não, [...] que mobilizam capitais econômicos, simbólicos, sociais e políticos [...] para criar e manter empreendimentos na área da cultura”.

Inspirados na noção weberiana de tipo-ideal, Michetti e Burgos (2016) diferenciam quatro tipos de empreendedores culturais, a saber: Empreendedor cultural por necessidade; por disposição; por opção; e, por vocação.

O “empreendedor cultural por necessidade" abrange grupos e indivíduos em situações precárias e de vulnerabilidade socioeconômica. A formalização como pessoa jurídica, quando ocorre, dá-se para o cumprimento de editais, emissão de notas fiscais ou solicitações de apoio a projetos culturais. Nesses casos, o empreendimento cultural é preterido à oportunidade de emprego formal e tende a ser marcado pela dedicação parcial e intermitência.

Diferentemente, para Michetti e Burgos (2016), os "empreendedores culturais por disposição" caracterizam-se por serem jovens adultos de classe média, diplomados em áreas criativas ou humanidades, artistas, produtores de conteúdo, ou que migram de outras áreas para a cultura, ou fazem dela uma ocupação complementar. A iniciativa de empreender culturalmente compreende seus estilos de vida, configura a tentativa de autorrealização e não submissão ao emprego formal.

O "empreendedorismo cultural por op̧̧ão", conforme Michetti e Burgos (2016), refere-se a indivíduos, empresas ou grupos empresariais que investem na produção de bens, serviços e eventos culturais com fim lucrativo. Por concentrar capital econômico, simbólico, social e político, tal tipologia tem maior acesso a recursos do setor público e privado. 
O "empreendedor cultural por vocação", segundo Michetti e Burgos (2016), diz respeito a artistas reconhecidos cuja consagração frequentemente foi galgada por meio de seu trabalho em organizações culturais ou de entretenimento consolidadas. Estes geralmente exercem outras atividades empreendedoras em paralelo ou como complemento à atividade de origem.

Há, no Brasil, para Michetti e Burgos (2016), uma concentração de recursos públicos destinados aos empreendedores culturais por opção e por vocação. No que concerne à legitimação e ao incentivo do discurso do empreendedor em projetos, programas e ações governamentais no país, os autores destacam: o Programa Nacional de Cultura Viva; Programa Incubadoras Brasil Criativo; Programa Banco Nacional de Desenvolvimento Econômico e Social para o Desenvolvimento da Economia da Cultura (BNDES/Procult); e, o Projeto de Economia Criativa estabelecido pela Agência Brasileira de Promoção de Exportações e Investimentos. Salientamos que é possível mencionar, ainda, enquanto ação governamental que incentiva e legitima o discurso do empreendedor cultural, a Campanha Cultura Gera Futuro, que será alvo de esforços analíticos neste trabalho.

\section{Método}

com o intuito de discutir, neste trabalho, a relação entre a ideia de empreendedor de si e a servidão voluntária dos artistas, abordamos para estudo o caso Cultura Gera Futuro. Acreditamos que a campanha federal possa fornecer dados atuais, representativos, abundantes e consistentes para amparar a compreensão da aproximação destes conceitos.

A opção pelo estudo de caso deu-se pela sua diferença fundamental às demais formas de pesquisa, que segundo Stake (2000), é a busca pela compreensão de uma unidade específica, situada em um determinado contexto. Desse modo, o estudo de caso não se trata apenas de uma escolha metodológica mas da escolha de um caso, fenômeno particular e/ou objeto que se pretende estudar de forma aprofundada.

Utilizamos o método de análise qualitativa, que se caracteriza, segundo Creswell (1998, p. 15), como “[...] um processo de investigação e entendimento baseado em tradições de investigação metodológicas que exploram o problema humano e social”, no qual “[...] o pesquisador constrói um quadro complexo e holístico, analisa palavras, reporta detalhadamente as visões de informantes e conduz o estudo em um campo natural".

Os dados primários foram coletados através de observação não participante na etapa do Circuito Cultura Gera Futuro, realizada na cidade de Florianópolis no dia 26 de abril de 2018. A coleta se deu a partir de gravação de áudio de aproximadamente 2 horas de discurso do ex-ministro, Sérgio Leitão, anotações no diário de campo e registros fotográficos do 
evento. Já a coleta dos dados secundários aconteceu por intermédio do grande destaque da campanha no site www.culturagerafuturo.com ${ }^{2}$, um portal sobre economia criativa no Brasil, com notícias, casos, agenda de eventos e cursos (BRASIL,2018). O corpus de análise dos dados secundários, obtidos no portal da campanha, foi constituído por 115 textos escritos de notícias e por 43 vídeos (textos orais), ambos publicados entre os dias 22 de fevereiro de 2018 e 6 de julho de 2018, totalizando 2 horas, 50 minutos e 28 segundos de falas.

Submetemos os dados coletados à análise de conteúdo proposta por Bardin (2016), a partir de categorias de análise definidas a posteriori, a saber: função salvacionista do empreendedorismo; empreendedorismo e trabalho artístico enquanto sinônimos; ações governamentais que legitimam o discurso do empreendedor de si.

\section{Discussões e análise}

Neste tópico, descrevemos os aspectos relacionados à Campanha Cultura Gera Futuro e discutimos, a partir deles, a respeito da existência do discurso do empreendedor de si enquanto um ideário sujeitador sobre as condições de trabalho, não apenas nas profissões sobre as quais a economia de mercado constituiu seu desenvolvimento, e a servidão voluntária dele decorrente.

\subsection{Cultura Gera Futuro}

Cultura Gera Futuro tratou-se de uma campanha lançada pelo Ministério da Cultura (MinC) no dia 16 de janeiro de 2018³. O objetivo do MinC com a promoção da campanha foi mobilizar a sociedade, por intermédio de diferentes meios de comunicação, em torno do tema Cultura Gera Futuro e apresentar a Cultura como "[...] ativo de imenso potencial: gera emprego, renda e inclusão social, e tem papel fundamental na promoção de um desenvolvimento mais justo e sustentável" (BRASIL, 2018, [s. p.]).

Para tanto, o ex-ministro Sérgio Sá Leitão solicitou que os produtores e empreendedores culturais passassem a exercer papéis de multiplicadores do conceito Cultura Gera Futuro. A campanha contou com vídeos, conteúdos para rádio e redes sociais, incluindo-se Facebook e Twitter, que têm sido transmitidos em cerca de 2.300 salas de cinemas no país, canais de televisão, aeroportos, e redes sociais. Entretanto, o grande destaque da campanha foi o site www.culturagerafuturo.com, um portal sobre economia criativa no Brasil, com notícias, casos, agenda de eventos e cursos (BRASIL, 2018).

Além dos meios anteriormente descritos, a Campanha Cultura Gera Futuro incluiu o Circuito Cultura Gera Futuro. Em tal circuito,
2 Atualmente, o site está desabilitado.

3 Destaca-se que, no mês de novembro do ano de 2018, o Ministério da Cultura, junto aos Ministérios do Esporte e do Desenvolvimento Social, foi extinto e passou a integrar o Ministério da Cidadania. Atualmente, a formulação de políticas, programas, projetos e ações relacionados à cultura, bem como a promoção do acesso aos bens culturais, da economia criativa brasileira e da proteção dos direitos autorais é de competência da Secretaria Especial de Cultura (BRASIL, 2019b). Tal secretaria, integrante do Ministério da Cidadania, teve suas competências atribuídas por intermédio do Decreto no 9.674, de 2 de janeiro de 2019 (BRASIL, 2019a). 
um representante do Ministério da Cultura percorreu as cinco regiões do Brasil, entre abril e julho do ano de 2018, com o objetivo de capacitar produtores culturais e gestores públicos para lidar com os mecanismos de fomento à cultura disponíveis no Governo Federal. As Equipes do MinC, nesse período, orientaram os participantes sobre a Lei Rouanet, a Lei do Audiovisual, o Fundo Setorial do Audiovisual (FSA) e outros mecanismos (BRASIL, 2018).

\subsection{Empreendedorismo e Servidão Voluntária: uma breve análise da Campanha Cultura Gera Futuro}

Ao considerarmos, com base em La Boétie (2009) que discursos proferidos, como aqueles sobre o bem público e o interesse geral podem atuar nos desejos dos sujeitos, inclusive naqueles considerados servis, tornase relevante a realização de um esforço analítico acerca da Campanha Cultura Gera Futuro. Conforme outrora relatado, tal campanha foi lançada pelo Ministério da Cultura no ano de 2018 e possui alcance nacional (BRASIL, 2018).

Ao analisarmos os textos escritos e orais disponíveis no site da campanha, pudemos perceber a promoção de uma noção da cultura enquanto recurso, aliada, principalmente, ao desenvolvimento econômico do Brasil. Conforme descrito, a cultura tem sido apresentada "como eixo de promoção do desenvolvimento econômico do Brasil” (BRASIL, 2018). O valor, a validade, a medida da relevância e do reconhecimento da cultura está vinculado, neste sentido, ao seu potencial de contribuição, sobretudo, econômica. O potencial social da cultura também é abordado, no entanto, em caráter secundário em detrimento do econômico.

Yúdice (2004) destaca que, a partir do século XX, passou a existir uma maior convergência da concepção de cultura à uma noção de recurso para melhoria sociopolítica e econômica. Nessa perspectiva, compreendemos que aquilo que se entende por cultura embasa a construção de políticas culturais. Circunstância percebida nos textos orais e escritos que compuseram o corpus de análise deste trabalho, e ainda mais evidente, naqueles em que o ex-ministro Sérgio Sá Leitão aborda as dimensões social e econômica quase que como sinônimos. Além disso, conforme enunciado por Leitão, há um interesse em apresentar a cultura não, primordialmente, como valor simbólico, e sim econômico (BRASIL, 2018).

O discurso atual tem sido difundido de maneira explícita e massiva. Os slogans da campanha que utilizam de palavras como, emprego, renda, desenvolvimento e futuro como ativos gerados pela cultura repetemse com frequência e são divulgados em aproximadamente 2.300 salas de cinemas no país, canais de televisão, aeroportos, e redes sociais. Aliada ao 
desenvolvimento econômico e difundida massivamente em todo o território nacional, a campanha apresenta também, nas palavras do ex-ministro da Cultura, a cultura enquanto "um investimento com retorno garantido para o país e para as empresas" e a política cultural, "sobretudo, como um cardápio de iniciativas de promoção de desenvolvimento econômico" (BRASIL, 2018). Tal situação corrobora o pensamento de Arienti (2003), quando o autor refere que a incorporação do discurso do chamado Estado neoliberal implica a subordinação da política social e econômica às demandas empresariais.

Entre as notícias apresentadas no site, encontram-se "casos de sucesso" de artistas que empreendem, "que geram renda, emprego, inclusão e desenvolvimento” (BRASIL, 2018). O empreendedorismo é apontado, por representantes do Estado, instituições públicas e privadas, por artistas renomados, e/ou trabalhadores culturais bem-sucedidos, com função salvacionista, redentora, capaz de transformar vidas, a sociedade e a economia. Casos como o de moradores de regiões de periferia que se tornam empresários do setor cultural ao participarem de projetos culturais e/ou de empreendedorismo são apresentados de modo recorrente. A infância dura é contraposta com o poder transformador da arte, com o poder da cultura que gera futuro (BRASIL, 2018).

Nessa circunstância, os indivíduos são estimulados a empreender, mas de maneira "legítima", ou seja, regulamentada, já que devido ao alto índice de excluídos do mercado, estes buscam oportunidades apelando para a atividade informal. Além disso, conforme dito anteriormente, de acordo com Gaulejac (2014), todos são convidados a se tornarem empreendedores, a gerenciar a sua carreira como uma pequena empresa. Na lógica desse discurso, o sujeito deve se converter em uma empresa e incorporar as características defendidas por ela (LAZZARATO, 2011). Não obstante, para serem reconhecidos como tais, é preciso ser produtivos e interiorizar os valores do mundo econômico, submetendo-se a eles (GAULEJAC, 2014).

Considerada acessível a todos, a carreira empreendedora de sucesso é vislumbrada como algo possível de ser conquistado, que não depende de características inatas, de questões socioeconômicas, como uma espécie de prêmio que aqueles que são diligentes e intrépidos o suficiente, como é possível perceber na fala do Enunciante 1:

Os anos de dedicação à cultura culminaram com sua volta ao mesmo prédio do CCBB do Rio, desta vez como diretor da peça Arandu. (MinC, 2018).

Eu não nasci empresária, eu não estudei empreendedorismo, não estudei marketing, não estudei nada disso. Ma, su fui percebendo, junto com a muisica e junto com as viagens que eu tava fazendo, o que eu gostaria de fazer da minha vida. (BRASIL, 2018). 
Circunstância esta, que reforça o argumento de que, ao invés da busca pelo controle sobre os corpos, assim como ocorria nos modos de produção, atualmente as formas de controle recaem sobre a mobilização psíquica a serviço do sistema (GAULEJAC, 2014; ENRIQUEZ, 2000), isto é, é preferível a adesão voluntária à sanção disciplinar, a responsabilidade à vigilância e a mobilização à obrigatoriedade. Nesse sentido, o controle é assimilado pelo trabalhador, assim como a responsabilidade por sua carreira, a culpabilização por seus erros, e a cobrança por desempenho, isto é, a emergência do indivíduo empreendedor de si como modelo ideal no mercado de trabalho: aquele indivíduo que vence por ele mesmo e é o único responsável tanto pelo seu sucesso como também pelo seu fracasso.

Gaulejac (2014) refere, ainda, que há uma preocupação em transformar energia libidinal em trabalho. Assim, cada um deve preencher seus objetivos com entusiasmo e determinação. Solicita-se permanentemente o desejo de sucesso, o gosto pelo desafio, necessidade de mérito pessoal. Procuram-se "winners" que possuem interesse pelo desempenho e sucesso, e que estejam dispostos a se doar de corpo e alma.

No portal da campanha, condições de trabalho precárias são apresentadas pelo Enunciante 2 com naturalização, como se fizessem parte da etapa inicial de uma carreira de sucesso:

Para fazer o show acontecer [...] tem que ser aquela tática de guerrilha, de ir para rua vender os ingressos, com o banner na mão e mostrar: $O$ vai ter esse show aqui, tal dia. Você se interessa em comprar o ingresso? E vender para a pessoa na hora. [...]. Quem vai ficar na bilheteria para mim é minha família. Tudo para ver se sobra alguma coisa. (BRASIL, 2018).

Destacamos que as circunstâncias anteriormente apresentadas não são consideradas exclusivas do contexto brasileiro e do caso mencionado. Ainda que estudos nacionais, como o desenvolvido por Nascimento e Dellagnelo (2018), apontem para uma precarização do trabalho artístico. Pesquisas realizadas em diferentes países, como àquelas elaboradas por Menger (2005), Benhamou (2007), Transform (2008), Banks, Gill e Taylor (2013), e Loacker (2013), mencionam que, via de regra, o trabalho artístico apresenta-se como formas de emprego precarizadas, trabalhos temporários - incluindo-se aqui projetos ou contratos de trabalho com vários clientes ao mesmo tempo -, e pela presença de poucos benefícios trabalhistas.

Destaca-se que, para Nascimento e Dellagnelo (2018), a atividade artística na região da grande Florianópolis, em Santa Catarina, tende a ser caracterizada como uma forma de trabalho em que há: um forte engajamento subjetivo; ausência de vínculos formais de trabalho; pouca ou nenhuma presença de benefícios trabalhistas assegurados pela Consolidação das Leis Trabalhistas (CLT); realização de atividades e/ou projetos com mais de um 
cliente ao mesmo tempo; variabilidade de renda; ritmo de trabalho intenso; vivência de uma fronteira porosa entre vida pessoal e trabalho; inseguranças financeiras; e existência de vínculos empregatícios (formais/informais) remotos com organizações.

Já Loacker (2013), em um estudo desenvolvido na Áustria com artistas de teatro, refere que diante de suas vocações e do nível de desemprego, inúmeros artistas consideram mais adequado diminuir o nível de resistência às condições de trabalho precárias e concordar com os lados obscuros de seu trabalho. Transform (2008) corrobora a visão de Loacker (2013), referindo que muitos artistas se sujeitam a condições de trabalho precárias sem oferecer resistência.

O emprego formal, estável, é exposto em caráter saudosista pelo Enunciante 3:

O emprego, como nós conhecíamos, não existe mais nem na quantidade, nem no nivel de remuneração que desejamos e merecemos. Nesse sentido, a capacitação e a formalização são essenciais para que, entre os milhares de profissionais autônomos, surjam novos empresários. (BRASIL, 2018).

Tal situação coaduna com a ideia de que o discurso do empreendedor de si pode ser relacionado ao contexto do capitalismo flexível, onde a ideia de longo prazo tem se tornado obsoleta (SENNETT, 2009), as figuras do trabalho autônomo e dos contratos temporários vêm sendo amplamente disseminadas, e o trabalho estável vem sendo substituído por diferentes e variados modos de informalidade.

Artistas e demais trabalhadores da área da cultura são denominados, nos textos orais e escritos, não como meros artistas, mas sim como empreendedores do meio cultural: "Sérjão Loroza e Dudu Nobre revelaram suas trajetórias não apenas como artistas, mas como empreendedores do meio cultural" (BRASIL, 2018). As descrições dos vídeos, com depoimentos de artistas e demais trabalhadores da cultura, no local onde constam as informações relacionadas à profissão dos sujeitos, quando mencionam suas atuações na esfera cultural, são seguidas de palavras relacionadas a empreendedor, empresário, proprietário ou outras funções de gestão.

De acordo com o Enunciante 4, o trabalho artístico é encarado como similar ao empreendedorismo, mescla-se a ele e é legitimado como tal:

A "móveis" foi uma banda onde eu aprendi não só a tocar e me colocar no palco, mas também foi esse lance de empreendedorismo muito forte. Nós éramos dez pessoas, então para a banda poder ser uma banda sustentável, a gente tinha que se virar nos trinta. Então, a gente montou uma PJ. Montou uma empresa. Trabalhava, fazia social, fazia não sei o que. Gerenciava a própria carreira. Quando a banda parou e tal, cada um se dividiu em dez frentes. (BRASIL, 2018). 
Para corroborar tal ideia, retomamos o pensamento de Menger (2005), que, ao discorrer sobre o trabalho artístico, alega que o artista tem sido percebido, nos dias atuais, quase como uma encarnação do trabalhador do futuro ou, como diria Loacker (2013), como um empreendedor, um sujeito ideal na era do capitalismo flexível.

Casos em que os artistas não conseguiram manter-se financeiramente, de caráter exclusivo, de sua arte são expostos. No entanto, a não subsistência da arte é tratada como algo trivial, tendo em vista que é possível empreender em outros segmentos do setor cultural:

A banda Móveis Coloniais de Acaju, uma das mais importantes formações do rock independente deste começo de milênio, optou por fazer um biato por tempo indeterminado em 2016. Mas os membros seguem atuantes e tirando sustento da economia criativa. (BRASIL, 2018).

Observamos ainda, a existência de dissimulação discursiva em algumas notícias, em que excertos de textos orais eram utilizados em contextos diferentes daqueles em que foram proferidos. Como exemplo podemos citar uma notícia acerca da Coutto Orchestra, cuja descrição divulgada pelo MinC (BRASIL, 2018) foi a seguinte: "Além da música, a Coutto Orchestra também tem 'sangue no olho', [...], para contribuir com o crescimento da economia criativa local. No vídeo referente a tal fala, o Enunciante 5 ressalta: "[...] eu me sinto feliz de estar num lugar pequenininho, mas com sangue nos olhos para estar enfrentando o mercadão, para estar expressando o que sente cada um [...]" (BRASIL, 2018).

$\mathrm{O}$ apoio e fomento ao empreendedorismo durante a campanha também se deu por intermédio da divulgação no portal de ações realizadas pelo MinC ou com o apoio deste, como: Cursos formativos voltados para o setor de games; Programa de formação Pernambuco criativo; Evento Economia Criativa Gera Futuro; e Condecoração pública da área da cultura (BRASIL, 2018).

O Ministério da Cultura em parceria com a Associação Brasileira dos Desenvolvedores de Jogos Digitais (Abragames) e o Núcleo de Estudos em Economia Criativa e da Cultura da Universidade Federal do Rio Grande do Sul (NECCULT-UFRGS) disponibilizaram uma série de três cursos em EAD voltados para a capacitação de futuros ou atuais profissionais do mercado de jogos eletrônicos (BRASIL, 2018).

No curso introdutório, "Setor de games: panoramas, carreiras e oportunidades", os participantes tiveram orientações de especialistas do Banco Nacional de Desenvolvimento Econômico e Social (BNDES), do Serviço Brasileiro de Apoio às Micro e Pequenas Empresas (Sebrae), da Agência Nacional do Cinema (Ancine) e da Spcine sobre como as pequenas desenvolvedoras de games podem obter sucesso (BRASIL, 2018). 
O segundo curso, "Dicas e desafios para empreendedores", foi organizado em torno de três eixos principais. $\mathrm{O}$ primeiro abordou o financiamento e monetização de games. $\mathrm{O}$ segundo eixo tratou das relações contratuais e com outros atores da indústria (desenvolvedoras, publicadoras). O terceiro eixo discutiu os desafios enfrentados pelos empreendedores do setor e como contorná-los (BRASIL, 2018).

Já no terceiro curso, "Internacionalização no setor de games", foi oferecida uma visão geral do processo de internacionalização e mostrou como o setor de games pode ser entendido nesse contexto. Foram, ainda, discutidas possibilidades de investimento que permitem impulsionar a atuação internacional dos desenvolvedores brasileiros, e apresentadas as características de potenciais mercados para a expansão das empresas brasileiras (BRASIL, 2018).

O programa de formação Pernambuco Criativo, foi iniciado no ano de 2017 por intermédio de uma parceria entre MinC, Fundação de Patrimônio Histórico e Artístico de Pernambuco (Fundarpe) e a Universidade Federal de Pernambuco (UFPE) (PERNAMBUCO, 2018). $\mathrm{O}$ intuito do programa, segundo divulgado no site da Campanha Cultura Gera Futuro é:

[...] oferecer atividades que atendam às necessidades/demandas da cadeia produtiva pernambucana, [...] e promover ações formativas para a contribuição do fomento à Economia da Cultura no Estado, que possui uma vocação natural para promoção de eventos e empreendimentos culturais. (BRASIL, 2018).

As atividades do programa de formação Pernambuco criativo permeiam temáticas, como: Produção e Gestão de Negócios Culturais (Direitos Culturais; Marketing, Comunicação e Relacionamento; Inovação em Cultura; Organização de Carreiras Artísticas; Redes, Sustentabilidade e Empreendedorismo); Processos e Organização dos Empreendimentos Culturais (Ferramentas Tecnológicas de Gestão; Metodologias Inovadoras para criação e gestão de negócios e empreendimentos culturais; Criação e gestão de e-commerce cultural) (BRASIL, 2018).

Outra ação destacada no portal da campanha foi o encontro Economia Criativa Gera Futuro. Promovido pelo MinC e a Central Única das Favelas (CUFA). Esse evento, realizado no Rio de Janeiro, criou "um grande debate sobre empreendedorismo, economia criativa e políticas públicas". $\mathrm{Na}$ ocasião, "moradores, artistas e empreendedores culturais locais" foram "capacitados" em relação a mecanismos de incentivo e fomento que o MinC oferece, como a Lei Rouanet e os editais de audiovisual (BRASIL, 2018).

No que concerne à principal condecoração pública da área da cultura, destacou-se que a Ordem do Mérito Cultural (OMC) - que reconhece desde 
1995, pessoas e instituições por suas contribuições ao desenvolvimento da cultura no país nos mais diversos segmentos culturais - no ano de 2017 teve como tema "Cultura, Inovação e Empreendedorismo" (BRASIL, 2018).

Apesar do enfoque atribuído ao empreendedorismo nas ações do Ministério da cultura e das principais realizações na gestão de Sérgio Leitão (o aumento do investimento do investimento via Lei Rouanet, Fundo Setorial de Audiovisual e Patrimônio Histórico), percebemos uma concentração de esforços em determinadas categorias de empreendedores. De fato, esta pesquisa corrobora os achados de Michetti e Burgos (2016), a saber: no Brasil os mecanismos de concentração de recursos públicos para os empreendedores culturais por opção e para os empreendedores culturais por vocação. Ressaltamos que, na etapa do Circuito Cultura Gera Futuro realizada na cidade de Florianópolis, foi também possível sugerir uma maior participação de tais categorias de empreendedores, sobretudo, daqueles ligados ao setor audiovisual.

Cabe salientar, por fim, o uso de termos que reforçam a ideia de empresa como um modelo universalmente generalizável, dentre eles: gestão, estratégia, networking, pitchings, soft power, showcases, potencial de agregação de valor, impacto econômico, curva de aprendizagem, eficiência e eficácia. Afinal, segundo Leitão, "a gestão é um meio sem o qual ninguém consegue fazer nada”. Afora esse apego ao modelo empresarial, Leitão também proferiu argumentos que legitimam a tentativa de redução do papel do Estado no âmbito cultural, principalmente no que diz respeito à lógica de incentivo, conforme explicita o Enunciante 6:

[...] ge gente entendeu que era possivel se dedicar com exclusividade àquilo e gerar uma rentabilidade que não tá só em viver em uma lógica de incentivo. Não é o incentivo que gera um sustento do artista. É necessariamente a relação com o público. (BRASIL, 2018).

Entretanto, na referida campanha, a diminuição do papel do Estado não é difundida de maneira uniforme, tendo em vista que microempreendedores formalizados, bem como outros tipos de pessoas jurídicas, devem continuar possuindo acesso e privilegiamento nos editais e nos mecanismos de fomento à cultura, pois geram "renda, emprego, inclusão e desenvolvimento. Acima de tudo, futuro" (BRASIL, 2018).

\section{Reflexões finais}

Buscamos, neste trabalho, discutir possíveis aproximações entre a ideia de empreendedorismo e a servidão voluntária dos trabalhadores artistas a partir da análise do Cultura Gera Futuro - campanha federal, amplamente veiculada, que centralizou as ações do Ministério da Cultura no ano de 
2018. Recorremos à análise de conteúdo de Bardin (2016) para analisar dados provenientes do site oficial da Campanha Cultura Gera Futuro e da observação não participante, na etapa do circuito referente à campanha, realizada na cidade de Florianópolis. Como arcabouço teórico, lançamos mão da obra "Discurso da Servidão Voluntária" de Étienne de La Boétie e de literaturas concernentes ao empreendedorismo e ao empreendedorismo cultural.

O material de análise de dados primários, obtidos a partir da observação não participante, foi constituído pela gravação de áudio de aproximadamente 2 horas de discurso do ex-ministro, Sérgio Leitão, anotações no diário de campo e de registros fotográficos realizados na etapa do Circuito Cultura Gera Futuro, realizada na cidade de Florianópolis. O corpus de análise dos dados secundários obtidos no portal da campanha foi constituído por 115 textos escritos de notícias e por 43 vídeos (textos orais), ambos publicados entre os dias 22 de fevereiro de 2018 e 06 de julho de 2018, totalizando 02 horas 50 minutos e 28 segundos de falas.

Destacamos que a análise da Campanha Cultura Gera Futuro levanta dados que auxiliam na compreensão de como o ideário sujeitador do neoliberalismo, influenciam nas condições de trabalho artístico e na manutenção da servidão voluntária dele decorrentes. Ao considerar que a construção do empreendedor como um modelo ideal de homem/ trabalhador pode buscar legitimar um ideário hegemônico, promovido por uma sociedade em que o mercado passa a ocupar e regular os demais espaços, esta pesquisa vislumbra esse ideário sujeitador como uma forma de manutenção do atual sistema econômico.

Nesse sentido, com base em Loacker (2013), observamos que o artista tem sido posicionado discursivamente como o trabalhador ideal, tendo em vista suas características atuais, seu contexto e sua dinâmica de trabalho que o aproximam da figura do empreendedor. Circunstância esta que tende a afetar as criações artísticas e a subjetividade de tal trabalhador (NASCIMENTO; DELLAGNELO, 2018), contribuindo para a sua sujeição ao discurso do trabalhador ideal, propagado pela acumulação flexível.

Verificamos que a precarização ocorrida no trabalho artístico e cultural tende a ser legitimada, frente à promoção da figura do artista como um modelo ideal de trabalhador/empreendedor. Circunstância que pode também ser analisada em outras profissões. Afinal, em meio às retiradas de direitos trabalhistas tão duramente conquistados, o discurso hegemônico que tende a responsabilizar os trabalhadores por suas carreiras e a induzilos a submissão às condições precárias, tem adquirido maior força. Desse modo, "a receita" para sobreviver nesta era de instabilidade indica que é preciso dispor de qualidades que irão ajudar esse indivíduo a virar-se por 
conta própria: manter-se empregável, ser flexível, criativo e ter um espírito empreendedor.

A Campanha Cultura Gera Futuro ilustra a utilização do discurso do empreendedor de si enquanto com função salvacionista, redentora, capaz de transformar vidas, a sociedade e a economia. Considerada acessível a todos, a carreira empreendedora de sucesso é vislumbrada como algo possível de ser conquistado, que não depende de características inatas, de questões socioeconômicas, como uma espécie de prêmio que aqueles que são diligentes e intrépidos o suficiente.

Ações governamentais, como aquelas relacionadas ao MinC e abordadas neste trabalho, incentivam e legitimam o discurso do empreendedor de si, no entanto, tais ações não são ofertadas de maneira homogênea a todos os tipos de empreendedores. Pelo contrário existem no Brasil mecanismos de concentração de recursos públicos nos tipos 3 - empreendedor cultural por opção - e 4 - empreendedor cultural por vocação. A propagada diminuição do papel do Estado também não é difundida de maneira uniforme, tendo em vista que microempreendedores formalizados, bem como outros tipos de pessoas jurídicas, possuem acesso e privilegiamento nos editais e nos mecanismos de fomento à cultura

Não obstante, consideramos que no capitalismo flexível o paradoxo de La Boétie, sofistica-se. A liberdade depara-se com outras formas de coerção, oriundas não apenas de fora, mas também impostas ao sujeito e pelo sujeito diante da assimilação do ideário neoliberal. Relegados a empresários ou gestores de si mesmos, os sujeitos são responsabilizados e culpabilizados por tudo o que acontece. Enquanto se colocam em posição servil, permitem que o outro faça uso de si, de seu corpo e subjetividade, a fim de não serem abandonados e caírem na solidão do desamparo. Domesticados ou servis ao ideário neoliberal, esses sujeitos devem demonstrar satisfação diante da precariedade em que vivem.

Ao considerarmos, com base em La Boétie (2009), que discursos proferidos - como aqueles sobre o bem público e o interesse geral - podem atuar nos desejos dos sujeitos, inclusive naqueles considerados servis, pudemos perceber que o discurso apresentado pelo MinC na Campanha Cultura Gera Futuro relaciona-se ao discurso em que o Estado, utilizando ardis legais ou pequenas compensações, busca produzir ilusões. A sujeição ao discurso do empreendedor de si, se analisada sob o prisma de La Boétie (2009), pode ser vislumbrada por três vias: Hábito, visto que, no processo de socialização, o humano abandona o estado de natureza, de modo que o desejo de liberdade cede lugar ao de servidão; Participação na Tirania, circunstância em que os humanos servem com o desejo de dominar; e Covardia, situação em que as pessoas servem porque se acham impotentes diante do tirano. 
O que pensar diante de tal conjuntura? Talvez refletir no pensamento de La Boétie (2009, p. 37) ilumine o contexto em que vivemos. Para tanto, sugerimos o seguinte excerto:

Quanto mais servimos mais se fortalecem e se tornam cada vez mais fortes e dispostos a aniquilar e destruir tudo. Mas basta não lhes dar nada e não lhes obedecer, sem combatê-los ou atacá-los, e eles ficarão nus e derrotados, e não são mais nada, assim como o ramo que, não tendo mais sumo nem alimento em sua raiz, seca e morre.

\section{Referências}

AKTOUF, O. Administração e teorias das organizações contemporâneas: rumo a um humanismo radical crítico? Organizações e Sociedade, v. 8, n. 21, p. 13-34, 2001.

ARIENTI, W. L. Do estado Keynesiano ao Estado Schumpeteriano. Revista de Economia Política, v. 23, n. 4, p. 92, out./dez. 2003.

BANKS, M.; GILL, R.; TAYLOR, S. Theorizing Cultural Work: labour, continuity and change in the cultural and creative industries. Nova Iorque: Routledge, 2013.

BARBOSA, A. M. S. O empreendedor de si mesmo e a flexibilização no mundo do trabalho. Revista de Sociologia e Política [online]., Curitiba, v.19, n.38, p. 121-140, 2011.

ARDIN, L. Análise de Conteúdo. São Paulo: Edições 70, 2016.

BENDASSOLLI, P. F. Público, privado e o indivíduo no novo capitalismo. Tempo Social, São Paulo, v. 12, n. 2, p. 203-236, 2000.

BENHAMOU, F. A economia da cultura. São Paulo: Ateliê Editorial, 2007.

BRASIL. Ministério da Cultura (MinC). Secretaria da Economia Criativa. Cultura Gera Futuro, 2018. Disponível em: http://culturagerafuturo.com. Acesso em: 6 ago. 2018.

BRASIL. Decreto no 9.674, de 2 de janeiro de 2019. Brasília: Presidência da República do Brasil, 2019a. Disponível em: http://cultura.gov.br/acesso-ainformacao/institucional/competencias. Acesso em: 24 de maio de 2019.

BRASIL. Ministério da Cidadania. Secretaria Especial de Cultura. Institucional, 2019b. Disponível em: http://cultura.gov.br/acesso-a-informacao/institucional. Acesso em: 24 maio 2019.

BRIENT, J. F.; FUENTES, V. L. Da servidão moderna. [s. 1.]: Editora independente, 2009.

CARVAlHO, C. M. B. DE; CUTRIM, K. D. G.; COSTA, S. R. da. Empreendedorismo cultural e turismo: perspectivas para desenvolvimento das indústrias criativas no bairro da Madre Deus, São Luís (Maranhão, Brasil). Boletim do Museu Paraense Emílio Goeldi - Ciências Humanas, v. 12, n. 2, p. 629-646, ago. 2017. 
CHAUI, M. Contra a servidão voluntária. 2. ed. Belo Horizonte: Autêntica; São Paulo: Fundação Perseu Abramo, 2014.

CHEUNG LEUNG, C. The development of cultural entrepreneurship: Case studies of four community orchestras in Hong Kong. Asian Education and Development Studies, v. 14, n. 2, p. 275-294, out. 2013.

COLBARI, A. A retórica do empreendedorismo e a formação para o trabalho na sociedade brasileira. SINAIS - Revista Eletrônica - Ciências Sociais, Vitória, v. 1, n. 0, Edição Especial de Lançamento, p.75-11, abr. 2007.

CRESWELL, J. W. Qualitative inquiry and research design: choosing among five traditions. Thousand Oaks, California: Sage Publications, 1998.

DARDOT, P.; LAVAL, C. A nova razão do mundo: ensaio sobre a sociedade neoliberal. São Paulo: Editora Boitempo, 2016.

DEJOURS, J. C. Nouvelles formes de servitude et suicide. Revue Internacionale de Psychopathologie et de Psychodinamique du travail, Paris, v. 13, n 1, p. 53-73, 2005.

DEJOURS, J. C. Trabalho vivo: Trabalho e emancipação (Tomo II). Brasília: Paralelo 15, 2012.

EHRENBERG, A. Culto da performance: da aventura empreendedora à depressão nervosa. Aparecida: Ideias e Letras, 2010.

ENRIQUEZ, E. O Indivíduo Preso na Armadilha da Estrutura Estratégica. In: MOTTA, F. P.; FREITAS, M. E. Vida Psíquica e Organização. Rio de Janeiro: FGV, 2000. p. 23-40.

FERREIRA, J. B. Patologias da Solidão. In: VIEIRA, F. de O.; MENDES, A. M.; MERLO, A. R. C. (Org.). Dicionário crítico de gestão e psicodinâmica do trabalho. Curitiba: Juruá, 2013. p. 275- 279.

FOUCAULT, M. Nascimento da biopolítica (1978-1979). São Paulo: Martins Fontes, 2008.

GAULEJAC, V. de. Gestão como Doença Social: Ideologia, poder gerencialista e fragmentação social. São Paulo: Ideias \& Letras, 2014.

GREEN, G. L. Marketing the Nation: Carnival and tourism in Trinidad and Tobago. Critique of Anthropology, v. 22, n. 3, p. 283-304, set. 2002.

KAVOUSY, E.; SHAHHOSSEINI, A., KIASI, S.; ARDAHAEY, F. T. Cultural entrepreneurship strategies in Iran. Serbian Journal of Management, v. 5, n. 2, p. 227-241, nov. 2010.

KHOURY,T. A.; PRASAD, A. Entrepreneurship Amid Concurrent Institutional Constraints in Less Developed Countries. Business \& Society, v. 55, n. 7, p. 934969, set. 2016.

KOVÁCS, I. Globalizações: novos rumos no mundo do trabalho. Florianópolis: Ed. da UFSC, 2001.

KREMP, P. A. Innovation and Selection: Symphony Orchestras and the Construction of the Musical Canon in the United States (1879-1959). Social Forces, v. 88, n. 3, p. 1051-1082, mar. 2010. 
LA BOÉTIE, E. de. Discurso da Servidão Voluntária. São Paulo: Martin Claret, 2009.

LAZZARATO, M. O governo das desigualdades: crítica da insegurança neoliberal. Tradução de Renato Abramowicz Santos. São Carlos: EduFSCar, 2011.

LINDKVIST, L.; HJORTH, D. Organizing cultural projects through legitimising as cultural entrepreneurship. International Journal Of Managing Projects In Business, v. 8, n. 4, p. 696-714, 2015.

LOACKER, B. Becoming "culturpreneur": How the "neoliberal regime of truth" affects and redefines artistic subject positions. Culture and Organization, Abingdon-UK, v. 19, n. 2, p. 124-145, 2013.

MENDES,A.M. Novas formas de organização do trabalho, ação dos trabalhadores e patologias sociais. In: MENDES, A. M. (Org.). Psicodinâmica do trabalho: teoria, método e pesquisas. São Paulo: Casa do Psicólogo, 2007. p. 49-61.

MENGER, P. M. Retrato do artista enquanto trabalhador: metamorfose do Capitalismo. Lisboa: Editora Roma, 2005.

MICHETTI, M.; BURGOS, F. Fazedores de cultura ou empreendedores culturais? Precariedade e desigualdade nas ações públicas de estímulo à cultura. Pol. Cult. Rev., Salvador, v. 9, n. 2, p. 582-604, jun./dez. 2016.

NASCIMENTO, M.; DELLAGNELO, E. H. L. Entre a Obrigação e o Prazer de Criar: uma análise Psicodinâmica do prazer-sofrimento trabalho artístico. REAd. Rev. eletrôn. adm., Porto Alegre, v. 24, n. 2, p. 135-166, ago. 2018. Disponível em: http://www.scielo.br/scielo.php?script=sci_arttext\&pid=S1413$23112018000200135 \& \operatorname{lng}=$ en\&nrm=iso. Acesso em: 24 maio 2019.

PAES DE PAULA, A. P. Tragtemberg revisitado: as inexoráveis harmonias administrativas e as burocracias flexíveis. Revista de Administração Pública, v. 36, n. 1, p. 127-144, jan./fev. 2002.

PERNAMBUCO. Secretaria de Cultura. Economia Criativa. Programa Pernambuco Criativo 2018 divulga propostas classificadas. 2018. Disponível em: http://www.cultura.pe.gov.br/canal/economiacriativa/programa-pernambucocriativo-2018-divulga-propostas-classificadas. Acesso em: 25 maio 2019.

ROSENFIELD, C. L. Trabalho decente e precarização. Tempo Social, v. 23, n. 1, p. 247-268, jun. 2011.

SARDANA, D. What Facilitates Cultural Entrepreneurship? - A Study of Indian Cultural Entrepreneurs. Journal of Creative Behavior, v. 52, n. 1, p. 35-51, mar. 2018.

SENNETT, R. A cultura do novo capitalismo. Rio de Janeiro: Record, 2009.

STAKE, R. E. Qualitative case studies. In: DENZIN, N. K.; LINCOLN, Y.S. (Ed.) Handbook of qualitative research. Thousand Oaks: SAGE, 2000, p. 443466.

TRANSFORM. Producción cultural y prácticas instituyentes: líneas de ruptura en la crítica institucional. Traficantes de Sueños: Madrid, 2008.

THROSBY, D. Defining the artistic workforce: the Australian experience. Poetics, v. 28, n. 4 , p. 255-271, 2001. 
ÜBERBACHER, F.; JACOBS, C. D.; CORNELISSEN, J.P. How Entrepreneurs Become Skilled Cultural Operators. Organization Studies, v. 36, n. 7, p. 925-951, jul. 2015.

YÚDICE, G. A Conveniência da Cultura: usos da cultura na era global. Belo Horizonte: Editora UFMG, 2004.

Submetido: 20/12/2018.

Aceito: 26/05/2019. 


\title{
THE VOLUNTARY SERVITUDE AND THE CULTURAL ENTREPRENEURSHIP SPEECH: POSSIBLE (SAD, MORE) APPROACHES
}

\begin{abstract}
The objective of this paper was to argue possible approaches between the idea of entrepreneurship and the voluntary servitude of the artists' workers, based on the analysis of the "Cultura Gera Futuro", a widely publicized federal campaign that centralized the actions of the Ministry of Culture in the year 2018. We used for the analysis of campaign content, data from the official website and non-participant observation held in the stage of dissemination circuit held in Florianópolis/SC. From the study, it was possible to demonstrate the linkage of the artist figure, in the "Cultura Gera Futuro", to the diffused image of self-entrepreneur, a discourse that reinforces and disseminates as positive and natural a sophisticated form of contemporary domination.
\end{abstract}

Keywords: Entrepreneurship. Artistic Work. voluntary servitude.

\section{LA SERVIDUMBRE VOLUNTARIA Y EL DISCURSO DE EMPRENDEDORISMO CULTURAL: APROXIMACIONES (TRISTES, MAS) POSIBLES}

\begin{abstract}
Resumen
En este trabajo, discutimos posibles acercamientos entre la idea de emprendedorismo y la servidumbre voluntaria de los trabajadores artistas a partir del análisis de la Cultura Gera Futuro - campaña federal, ampliamente difundida, que centralizó las acciones del Ministerio de Cultura en el año 2018. Utilizamos para análisis del contenido de la campaña dados del sitio oficial y de la observación no participante realizada en la etapa de circuito de divulgación realizada en Florianópolis/SC. En el estudio, la vinculación de la figura del artista, en la Cultura Gera Futuro, a la imagen difundida de emprendedor de sí, discurso que refuerza y disemina como positiva y natural una forma sofisticada de dominación contemporánea.
\end{abstract}

Palabras clave: Emprendedor. Trabajo artístico. Servidumbre voluntaria. 